Article

\title{
A Hybrid Multi-Objective Optimization Framework for Preliminary Process Design Based on Health, Safety and Environmental Impact
}

\author{
Shin Yee Teh ${ }^{1}$, Kian Boon Chua ${ }^{1}$, Boon Hooi Hong ${ }^{1}$, Alex J. W. Ling ${ }^{1}$, Viknesh Andiappan ${ }^{2}{ }^{(}$, \\ Dominic C. Y. Foo ${ }^{1}{ }^{\circledR}$, Mimi H. Hassim ${ }^{3}$ and Denny K. S. $\mathrm{Ng}^{1,2, * \mathbb{C}}$ \\ 1 Department of Chemical and Environmental Engineering/Centre of Excellence for Green Technologies, \\ The University of Nottingham Malaysia, Broga Road, Semenyih 43500, Malaysia; \\ shinyee30@gmail.com (S.Y.T.); kianboon19@gmail.com (K.B.C.); b0onhui@hotmail.com (B.H.H.); \\ alex1215.aiesec@gmail.com (A.J.W.L.); Dominic.Foo@nottingham.edu.my (D.C.Y.F.) \\ 2 School of Engineering and Physical Sciences, Heriot-Watt University Malaysia, Putrajaya 62200, Malaysia; \\ v.murugappan@hw.ac.uk \\ 3 School of Chemical and Energy Engineering/Centre of Hydrogen Energy, Universiti Teknologi Malaysia, \\ Johor Bahru 81310, Malaysia; mimi@cheme.utm.my \\ * Correspondence: Denny.Ng@hw.ac.uk; Tel.: +603-8894-3784
}

Received: 25 February 2019; Accepted: 25 March 2019; Published: 8 April 2019

\begin{abstract}
Due to increasingly stringent legal requirements and escalating environmental control costs, chemical industries have paid close attention to sustainable development without compromising their economic performance. Thus, chemical industries are in need of systematic tools to conduct sustainability assessments of their process/plant design. In order to avoid making costly retrofits at later stages, assessments during the preliminary design stage should be performed. In this paper, a systematic framework is presented for chemical processes at the preliminary design stage. Gross profit, Health Quotient Index (HQI), Inherent Safety Index (ISI) and the Waste Reduction (WAR) algorithm are used to assess the economic performance, health, safety and environmental impact of the process, respectively. The fuzzy optimization approach is used to analyse the trade-off among the four aspects simultaneously, as they often conflict with each other. Deviation between the solution obtained from mathematical optimization model and process simulator is determined to ensure the validity of the model. To demonstrate the proposed framework, a case study on 1, 4-butanediol production is presented.
\end{abstract}

Keywords: input-output model; fuzzy optimization; process synthesis; preliminary stage design

\section{Introduction}

Process design is a core element in the field of chemical engineering. It can be considered a centre point, bringing together all chemical engineering components as a whole. Process design is associated with creating processes or improving existing processes. An integral part of process design is process synthesis. Process synthesis is defined as "the discrete decision-making activities of conjecturing (1) which of the many available component parts one should use, and (2) how they should be interconnected to structure the optimal solution to a given design problem." [1]. The field of process synthesis has seen significant developments since its inception in the 1960s led by the late Roger W. H. Sargent [2]. Most notably, key pioneering contributions have been an integral part of establishing what process synthesis is and what it entails. For instance, Nishida et al. [3] provided an important overview of developments within the boundary of process synthesis and defined process synthesis as "an act of determining the optimal interconnection of processing units as well as the optimal type 
and design of the units within a process system". Meanwhile, the Onion model [4] was proposed as a systematic overview and guide to process synthesis thinking. The Onion model emphasized that a reactor is designed first followed by separation and recycle streams, heat recovery systems and utility systems [4]. Foo and $\mathrm{Ng}$ [5] then extended the Onion model further by incorporating material recovery and treatment systems (see Figure 1). On the other hand, Douglas' model is another well-accepted decision hierarchy approach that was proposed for process synthesis in the late 80s [6].

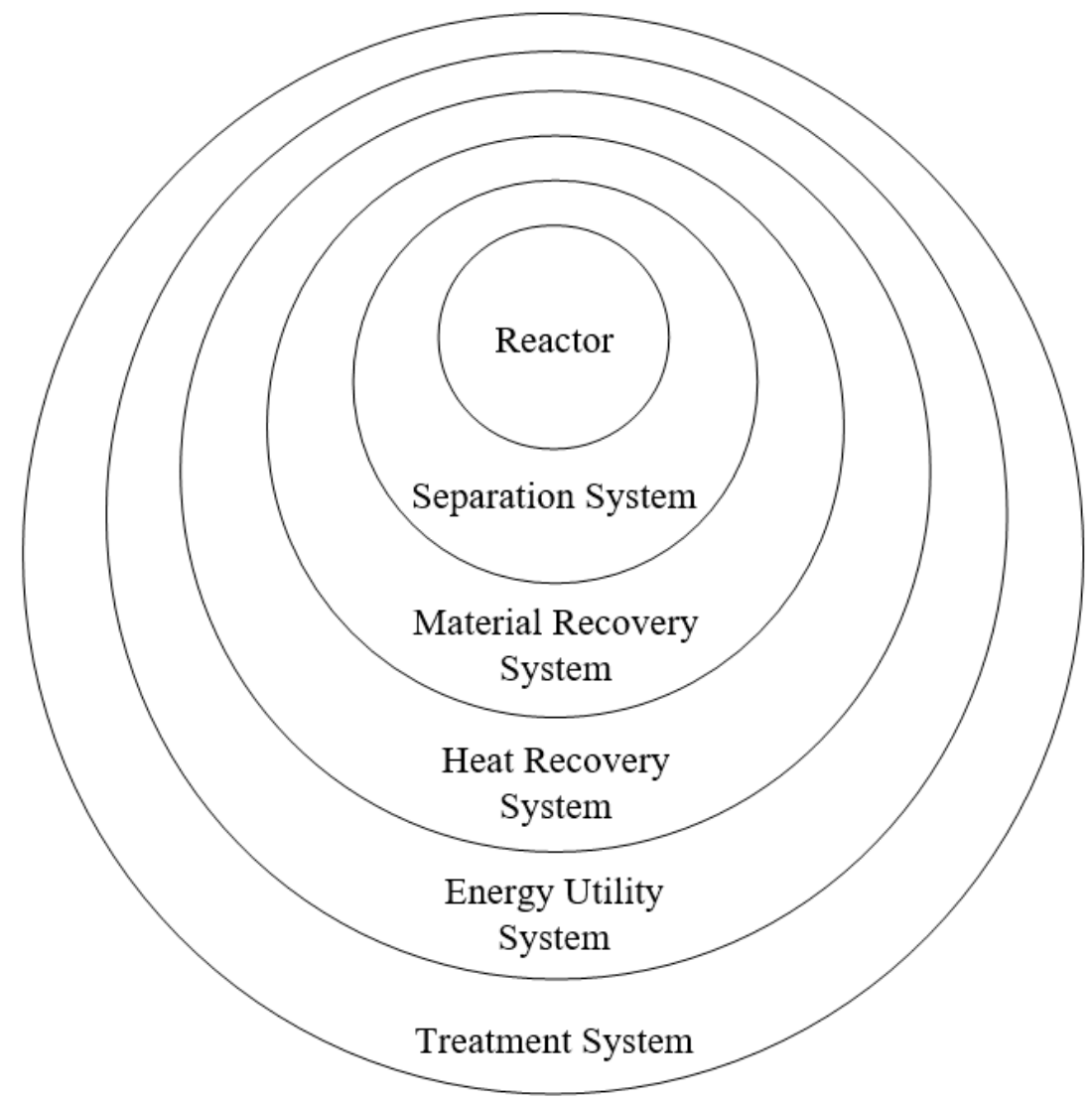

Figure 1. The extended Onion Model [5]. Reproduced with permission from Foo, D.C.Y.; Ng, D.K.S., Process Integration for Cleaner Process Design; In Handbook of Process Integration: Minimisation of Energy and Water Use, Waste and Emissions; published by Elsevier Science, 2013.

To date, there has been a vast number of developed process synthesis methodologies. Often, these methodologies pay close attention to the technical and economic performance of a process design. Meanwhile, other aspects such as safety, occupational health and environmental impacts are typically considered at the later/final stages of design $[7,8]$. However, several papers argue that these aspects should be considered at the preliminary stage of process synthesis as the cost of process improvement and operational risks can be significantly lowered compared to at the later stages (detailed design) $[9,10]$. In this respect, several alternative methods for evaluating occupational health, safety and environmental impacts have been presented.

In the area of safety evaluations, Edwards and Lawrence [11] developed the earliest method for assessing inherent safety in a given process. This method is known as Prototype Index of Inherent Safety (PIIS). PIIS ranks the inherent safety level of alternative chemical process routes based on main reactions and parameters such as pressure, temperature, yield, heat of reaction, inventory, flammability, toxicity and explosiveness. Despite considering the mentioned parameters, PIIS focuses solely on the main reaction of a process and not the other parts of the process. In view of this, Heikkila [12] proposed an alternative approach called the Inherent Safety Index (ISI). ISI considers the same factors as in the PIIS along with additional ones such as corrosions, side reactions, and inventory for both inside 
and outside the battery limits, types of equipment and process structure. Later, Palaniappan et al. [13] added a few supplementary indexes such as worst reaction index, overall chemical index and total chemical index to the previously proposed ISI to form $i$-Safe.

Aside from safety, various methods have been developed to evaluate occupational health. For example, Hassim and Edwards [14] developed Process Route Healthiness Index (PRHI) to rank the process alternatives based on the potential of working activities and process conditions that may harm workers. However, PRHI is not suitable for assessment in the preliminary design stage, as it requires complete process information (e.g., points for manual handling etc.). In this respect, Hassim et al. developed the Inherent Occupational Health Index (IOHI) [10], which is suitable for application at the initial stage of the process research and development (R\&D). This work was then extended to a more detailed assessment called the Health Quotient Index (HQI), which uses detailed process information available in the preliminary design stage [15]. HQI is able to rank the process alternatives based on health risk values from the fugitive emissions and to calculate the risk of a given process.

Apart from occupational health, there are many well-established approaches reported in the literature on environmental impact assessments. The Environmental Hazard Index (EHI) [16] and Atmospheric Hazard Index (AHI) [17] are among the early methods that assess inherent environmental performance of chemical process routes. Later, Gunasekera and Edwards [18] integrated EHI with AHI into a new method which is known as Inherent Environmental Toxicity Hazard (IETH). IETH can estimate the inherent environmental friendliness of a chemical plant in all media including air, soil and aquatic due to total loss of contaminants. Cabezas et al. [19] then introduced the generalized Waste Reduction (WAR) algorithm. This algorithm determines the total environmental impacts based on the Potential Environmental Index (PEI) balance, which assigned environmental impact values to different pollutants. Young and Cabezas [20] extended PEI balance to integrate the energy consumption of the chemical process into the environmental evaluation. Similarly, Andiappan et al. [21] presented the incremental environmental burden assessment (IEBA), which used the concept of economic potential assessment method developed by Seider et al. [22] to determine the new environmental burden for each process.

It is essential to note that the abovementioned evaluation methods focus only on assessing the performance of a process design based on just one aspect (e.g., safety or occupational health or environmental impact) and not addressing them simultaneously. In this respect, there have been attempts to develop process synthesis approaches that address safety, occupational health and environmental impacts simultaneously. For instance, Azapagic et al. [8] and Othman et al. [23] presented sustainable assessment and design selection approaches that consider economic, environmental, and social aspects. Besides, Al-Sharrah et al. [24] presented a multi-objective optimization model which considers environmental impact, economic performance and operational risk simultaneously for the petrochemical industry. Liew et al. [25] developed a systematic approach to the screening of sustainable chemical reaction pathways at the research and development (R\&D) stage. Based on the proposed approach, fuzzy optimization is used to trade-off economic performance, health, safety and environmental impact. Similarly, Ng et al. [26] presented a multi-objective process synthesis approach which considered economic performance, health, safety and environmental impact for biorefineries. Following this, a visualization tool called the Piper diagram was also proposed for considering economic, safety and environmental aspects simultaneously [27]. However, due to its graphical nature, the Piper diagram is unable to consider process optimization.

It is clear that the abovementioned work presents approaches to evaluate safety, occupational health and environmental impacts at the preliminary stage of design. However, these approaches focus on preliminary screening without considering operating conditions in a given process. The choice of process operating conditions has a process direct impact on screening decisions and this should be given closer attention. To address this, process simulators can be used to analyse operating conditions for a given process. Process simulators can be used to represent chemical processes in terms of mathematical models and solve them to attain insights on their performance [28]. Process simulation 
is an essential and complementary task of process synthesis, as it predicts how a process design would behave under defined operating conditions [29,30]. Despite the benefits of process simulators, they suffer from various limitations. For instance, simulators are limited to considering a single objective (e.g., product yield or production rate) at a given run. This limitation disables simulators from finding a trade-off between multiple aspects such as process economics, occupational health, safety and environmental impacts for a given process design. In order to consider multiple aspects simultaneously, multi-objective optimization is required.

As such, this paper presents a systematic framework which combines the benefits from both process simulation and multi-objective optimization to address economic, environmental, health and safety aspects simultaneously at the preliminary design stage. This paper is structured as follows: First, a formal problem statement is given in Section 2. A systematic framework for preliminary process design is presented in Section 3; To illustrate the proposed framework, a case study on the screening of 1,4-butanediol production processes is presented in Section 4; and the work is finally concluded in Section 5.

\section{Problem Statement}

The problem addressed in this work is stated as follows; given a set of alternative processes $k$ to produce chemical product (in a given output stream) $p$. Each alternative process $k$ has a set of unit operation $j$ with operating capacities, $x_{j, k}$ and a set of (output) stream $p$ to or from unit operation $j$ represented by matrix $a_{p, j, k}$. Alongside this, each alternative process $k$ differs in economic performance, health, safety and environment impacts. In this work, four objectives are considered for performing a preliminary evaluation and screening of alternative process $k$. The economic performance is determined based on the gross profit of alternative process $k$ (GP). The health impacts of process alternative $k$ are evaluated using Health Quotient Index (HQI). Meanwhile, the safety and environmental impact of each alternative process $k$ are determined via Inherent Safety Index (ISI) and Potential Environmental Index (WAR) respectively.

This work combines the advantages of process simulation, input-output modelling (IOM) and fuzzy optimization to determine the trade-off between the GP, HQI, ISI and WAR objectives. In fuzzy optimization, the degree of satisfaction $\left(\lambda_{k}\right)$ is introduced to quantify the degree of satisfaction for four objectives in each alternative process $k$. Following this, the alternative process $k$ with the highest $\lambda_{k}$ will be selected. A detailed description of the proposed framework to address the stated problem is presented in the following section.

\section{Framework for Preliminary Process Design}

Figure 2 presents the proposed framework for preliminary process design, which considers economic performance, health, safety and environment impacts simultaneously. As shown, the proposed framework begins by identifying the product $i$ that is expected to be produced. Next, alternative process $k$ which produce product $i$ is determined. In order to analyse the performance of each alternative process $k$, process simulation tools (e.g., Aspen HYSYS, SuperPro Designer, PRO/II, etc.) can be used to simulate the process. Based on the simulation results, process data such as mass flow rates and energy requirements for each process unit $j$ can be determined. These data are then used to develop an input-output model for each process. Input-output model was presented by Leontief $[31,32]$ to analyse the relationship among the raw materials requirement, goods production and the exchange of materials within different economic sectors. Tan et al. [33] extended the usage of input-output model in life cycle assessment and ecological footprint analysis. Aviso et al. [34] integrated the approach with optimization framework to analyse the eco-industrial supply chain under a water footprint constraint. Recently, the input-output model has been used to describe the material and energy balance of processes in a system [35]. Based on the approach [35], the optimal operational adjustment in multi-functional energy systems in response to process inoperability can be determined. Kasivisvanathan et al. [36] also used the input-output model with robust optimization for 
process synthesis and design of multi-functional energy systems with uncertainties. Most recently, Foong et al. [37] extended the use of the input-output model for sustainable oil palm plantation development. A detailed description on the procedure to develop an input-output model is presented with an example in Andiappan et al. [38]. The input-output model for each alternative process $k$, given as in Equation (1)

$$
\sum_{j=1}^{J} \mathrm{a}_{p, j, k} x_{j, k}=y_{p, k} \forall p \forall k
$$

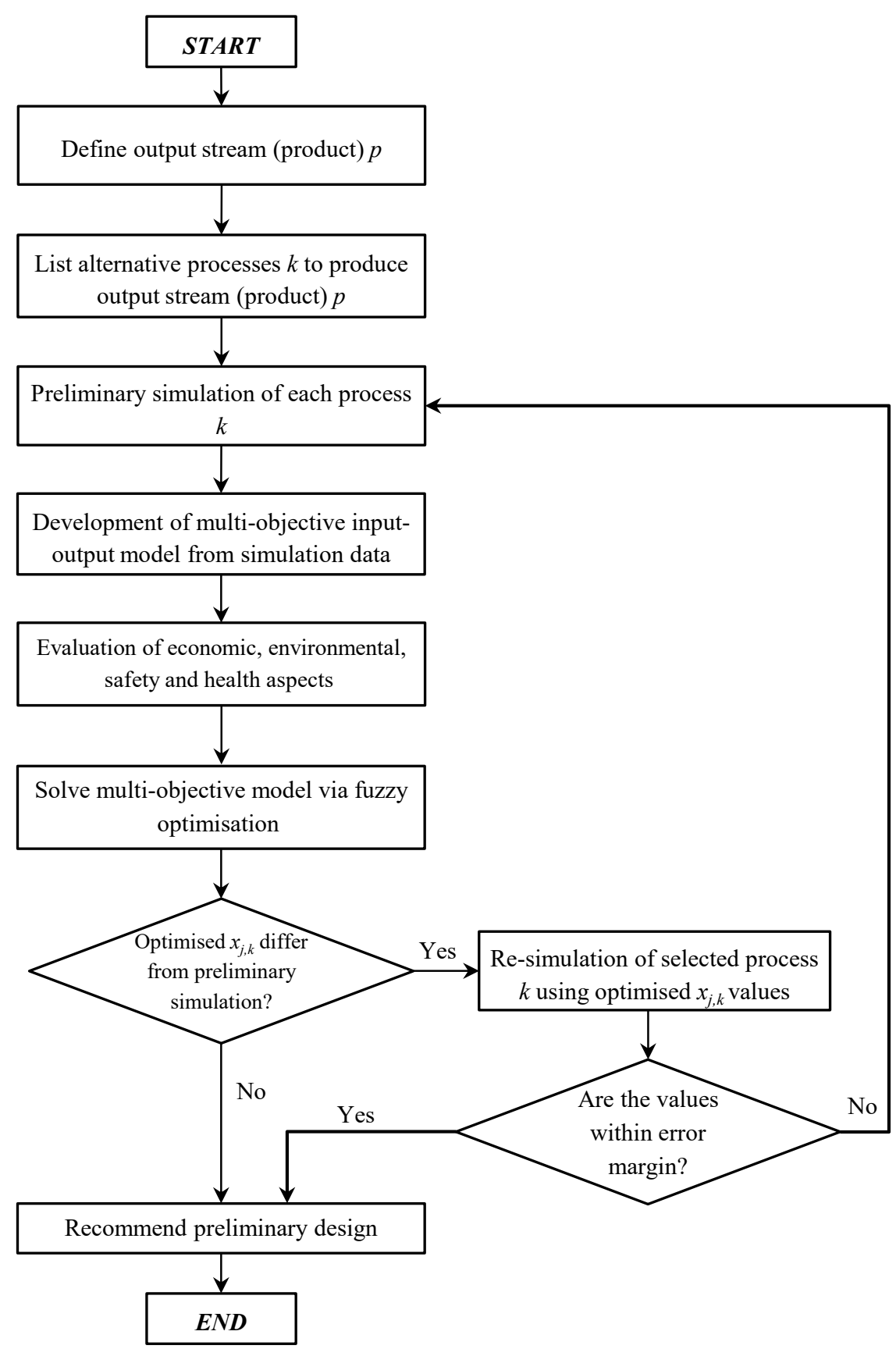

Figure 2. Systematic design framework for preliminary process design.

In Equation (1), $a_{p, j, k}$ represents the matrix of input or output mass flow rate of stream $p$ to/from unit operation $j$ in process $k . x_{j, k}$ represents the capacity or size of the unit operation $j$ in process $k$ and $y_{p, k}$ is the net output of stream $p$ in process $k$. A positive value of $y_{p, k}$ indicates that it is an output 
stream which is either product or effluent stream whereas a negative value indicates that it is an input stream and a value of zero denotes that it is an intermediate stream.

Meanwhile, the lower and upper limits of the capacity of unit operation $j$ in process $k$ are presented in Equation (2):

$$
\mathrm{x}_{j, k}^{\mathrm{L}} \leq x_{j, k} \leq \mathrm{x}_{j, k}^{\mathrm{U}} \forall j \forall k
$$

In addition to Equations (1) and (2), the economic, environmental, health and safety impact for each process $k$ is determined. Firstly, in this work, economic performance for each process $k$ is measured via gross profit as shown in Equation (3):

$$
G P_{k}=\left(\sum_{p=1}^{P} y_{p, k}^{\text {Prod }} C_{p, k}^{\text {Prod }}+\sum_{p=1}^{P} y_{p, k}^{\text {Raw }} C_{p, k}^{\text {Raw }}\right) \text { AOT }_{k} \forall k
$$

where $y_{p, k}^{\text {Prod }}$ and $y_{p, k}^{\text {Raw }}$ are the mass flow rate of the products and raw materials in process $k$ respectively; $\mathrm{C}_{p, k}^{\text {Prod }}$ and $\mathrm{C}_{p, k}^{\mathrm{Raw}}$ are the product price and cost of raw materials in process $k$ respectively; $\mathrm{AOT}_{k}$ is the annual operating time for process $k$. Note that $y_{p, k}^{\text {Raw }}$ is obtained from the input-output model as a negative value. This is because it is an input stream into the system, as stated previously in Equation (1).

On the other hand, the environmental impact of each process $k$ is also evaluated. For this work, the WAR algorithm is adapted to evaluate the environmental impact because it can determine the average possible impact of a chemical process on the environment, based on environmental impact values of different pollutants and their respective mass flows. According to the WAR algorithm, the total environmental impact generated by process $k, W A R_{k}$ can be expressed as in Equation (4) as follows.

$$
W A R_{k}=i_{k}^{(\mathrm{cp}), \text { out }}+i_{k}^{(\mathrm{cp}), \text { in }}+i_{k}^{(\mathrm{ep}), \mathrm{out}} \forall k
$$

where $i_{k}^{(\mathrm{cp}) \text {,in }}$ and $i_{k}^{(\mathrm{cp}), \text { out }}$ are the input and output rates of impact in the process $k, i_{k}^{(\mathrm{ep}), \text { out }}$ is the power consumption for process $k$. The value of $i_{k}^{(\mathrm{cp}), \text { out }}, i_{k}^{(\mathrm{cp}), \text { in }}$ and $i_{k}^{(\mathrm{ep}), \text { out }}$ are determined through Equations (5)-(9) respectively:

$$
\begin{gathered}
i_{k}^{(\mathrm{cp}), \text { out }}=\sum_{i=1}^{I} y_{i, k}^{\mathrm{Out}} \sum_{a=1}^{A} \sum_{j=1}^{J} w_{a, j, k} P E I_{a} \forall k \\
i_{k}^{(\mathrm{cp}) \text {,in }}=\sum_{i=1}^{I} y_{i, k}^{I n} \sum_{a=1}^{A} \sum_{j=1}^{J} w_{a, j, k} P E I_{a} \forall k \\
i_{k}^{\text {(ep),out }}=\sum_{i=1}^{I}-y_{i, k}^{E l e c} P E I^{\mathrm{Elec}} \forall k \\
P E I_{a}=\sum_{l=1}^{L} \alpha_{l} \mathrm{PEI}_{a, l} \forall k \\
P E I^{\text {Elec }}=\sum_{l=1}^{L} \alpha_{l} \mathrm{PEI}_{l}^{\text {Elec } \forall k}
\end{gathered}
$$

where $y_{i, k}^{\text {Elec }}$ is the power consumption of process $k ; P E I_{a}$ and $P E I^{\text {Elec }}$ are the score of the potential environmental impact of chemical component $a$ and electricity respectively; $\alpha_{l}$ is the weighting factor of the impact at category $l ; \mathrm{PEI}_{a, l}$ and $P E I_{l}^{\text {Elec }}$ are the potential environmental impact score of chemical component $a$ and electricity at each of the category $l$ respectively. Note that a total of eight categories are considered for PEI, that is, human toxicity potential by exposure, both dermal and inhalation (HTPE), 
human toxicity potential by ingestion (HTPI), aquatic toxicity potential (ATP), terrestrial toxicity potential (TTP), ozone depletion potential (ODP), global warming potential (GWP), acidification potential (AP) and photochemical oxidation potential (PCOP).

In order to evaluate the health impact of process $k$, the Hazard Quotient Index (HQI) is selected for this work. This is because HQI can be used for simple process flow diagrams (PFDs) containing limited information, namely process drawings and process descriptions. Such method is suitable for the case of preliminary process design optimization as it allows for the comparison of alternative processes by ranking them based on the risk value based on minimal available information. The calculation of HQI consists of four parts, i.e., estimation of fugitive emissions, air volumetric flow rate, airborne chemical concentration and the health risk (HQI) value. Fugitive emission of each of the chemical components $a$ in process $k, m_{a, k}$ can be calculated via Equation (10):

$$
m_{a, k}=\sum_{j=1}^{J} \sum_{p=1}^{P} x_{j, k}^{0.5} \mathrm{w}_{a, j, k} \mathrm{FE}_{p, j, k} \forall a \forall k
$$

where $x_{j, k}, \mathrm{w}_{a, j, k}$ and $\mathrm{FE}_{p, j, k}$ are the capacity of the unit operations $j$, weight composition of chemical component $a$ and the estimated fugitive emission rates in stream $p$ to or from unit operation $j$ respectively. The pre-calculated fugitive emission rates database for the unit operation stream can be obtained from Hassim et al. [15]. The air volumetric flow rate is determined by the following Equations (11)-(14).

$$
\begin{gathered}
\mathrm{A}_{k}^{\mathrm{T}}=\sum_{j=1}^{J} \mathrm{~A}_{j, k} \forall k \\
s_{k}=\left(\mathrm{A}_{k}^{\mathrm{T}}\right)^{\frac{1}{2}} \forall k \\
\mathrm{~A}_{k}^{\mathrm{c}}=h_{k} s_{k} \forall k \\
\mathrm{Q}_{k}=\mathrm{vA}_{k}^{\mathrm{c}} \forall k
\end{gathered}
$$

where $\mathrm{A}_{k}^{\mathrm{T}}$ and $\mathrm{A}_{j, k}$ are the total process floor area and the floor area of each unit operations $j$ in process $k$ respectively; $s_{k}$ is the side length of the process $k ; \mathrm{A}_{k}^{\mathrm{c}}$ is the cross-sectional area of the process; $h_{k}$ is the average height of the main unit operations in process $k ; Q_{k}$ is the air volumetric flow rate; $v$ is the wind speed. The average concentration of the chemical components in the air at the downwind edge of the plot area, $C_{a, k}$ can be determined using Equation (15):

$$
C_{a, k}=\frac{m_{a, k}}{\mathrm{Q}_{k}} \forall a \forall k
$$

HQI of component $a$ in process $k$ can be calculated using Equations (16) and (17):

$$
\begin{gathered}
H Q I_{a, k}=\frac{C_{a, k}}{C_{a}^{E L}} \forall a \forall k \\
H Q I_{k}=\sum_{a=1}^{A} H Q I_{a, k} \forall k
\end{gathered}
$$

where $H Q I_{a, k}$ is the HQI of each chemical components $a ; C_{a}^{\mathrm{EL}}$ is a constant which represents the threshold limit of the chemical component $a ; H Q I_{k}$ is the total HQI of process $k$.

The safety impact of a process is assessed via Inherent Safety Index (ISI). ISI is selected because it is a simple scoring method that can be incorporated into an optimization framework. Moreover, ISI considers all parts of the process and equipment, unlike the PIIS method. The total ISI score for 
process $k$ is represented by $\operatorname{ISI}_{k}$. ISI $I_{k}$ is calculated by summing the Chemical ISI, $I_{k}{ }^{\mathrm{CI}}$ and Process ISI, $I_{k}{ }^{\mathrm{PI}}$ as shown in Equation (18):

$$
I S I_{k}=I_{k}^{\mathrm{CI}}+I_{k}^{\mathrm{PI}} \forall k
$$

The sub-index for Chemical ISI, $I_{k}{ }^{C I}$ is expressed as below:

$$
I_{k}^{\mathrm{CI}}=I_{k}^{\mathrm{RM}, \max }+I_{k}^{\mathrm{RS}, \max }+I_{k}^{\mathrm{INT}, \max }+I_{k}^{\mathrm{FL}, \max }+I_{k}^{\mathrm{EX}, \max }+I_{k}^{\mathrm{TOX}, \max }+I_{k}^{\mathrm{COR}, \max } \forall k
$$

where $I_{k}^{\mathrm{RM}, \max }, I_{k}^{\mathrm{RS}, \max }, I_{k}^{\mathrm{INT}, \max }, I_{k}^{\mathrm{FL}, \max }, I_{k}^{\mathrm{EX}, \max }, I_{k}^{\mathrm{TOX}, \max }$ and $I_{k}^{\mathrm{COR}, \max }$ are the sub-index for the factor of the heat of main reaction, heat of side reaction, chemical interaction, flammability, explosiveness, toxic exposure and corrosiveness of the chemical components present in the process $k$ respectively. The sub-index for process ISI, $I_{k}{ }^{\mathrm{PI}}$ is given as:

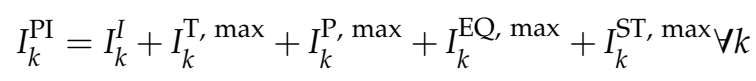

where $I_{k^{\prime}}^{\mathrm{I}} I_{k}^{\mathrm{T}, \max }, I_{k}^{\mathrm{P}, \max }, I_{k}^{\mathrm{EQ}, \max }$ and $I_{k}^{\mathrm{ST}, \max }$ are the sub-index for the factor of inventory, process temperature, process pressure, equipment safety and safe process structure, respectively. The calculations for both $I_{k}{ }^{\mathrm{CI}}$ and $I_{k}^{\mathrm{PI}}$ are performed on the basis of the worst-case scenario. Among all chemical components present in the process, the scores of the chemical with the most severe hazard in terms of flammability, explosiveness and toxicity are used in the $I_{k}{ }^{\mathrm{CI}}$ calculation. Besides, the highest temperatures of the main and side reaction and the worst possible chemical substance interaction in the process are considered. Meanwhile, the maximum expected values for inventory, process temperature, and pressure and the worst process structure are taken into account for the calculation of $I_{k}$ PI . The sub-index for inventory is influenced by the total output of the process, $y_{k}^{\text {Out }}$ which is calculated using Equation (21):

$$
y_{k}^{\text {Out }}=\sum_{p=1}^{P} y_{p, k}^{\text {Out }} \forall k
$$

where $y_{p, k}^{\text {Out }}$ is the mass flow rate of the output stream for product and effluent streams. The score of the sub-index for inventory is assigned using Equations (22) and (23) [39]. In Equation (22), $\mathrm{L}_{\mathrm{k}, r}$ and $\mathrm{U}_{\mathrm{k}, r}$ are the lower and upper bounds of a given criteria $r$. The criteria $r$ can often be in the form of a range. For instance, $r=1$ may refer to the criteria where mass flowrate is between the range of $300-500 \mathrm{~kg} / \mathrm{hr}$. In this context, $300 \mathrm{~kg} / \mathrm{hr}$ would be $\mathrm{L}_{\mathrm{k}, r}$ and $300 \mathrm{~kg} / \mathrm{hr}$ would be $\mathrm{U}_{\mathrm{k}, r}$. If $y_{p, k}^{\text {Out }}$ falls between this range $r$ $=1$ or meets this criteria, Equation (22) will assign a specific score $S_{k, r}$, which is activated by binary variable $b_{k, r}$.

$$
\begin{gathered}
\left(\mathrm{L}_{k, r}-\mathrm{U}_{k, r}\right) \times b_{k, r}<y_{k}^{\text {Out }}-\mathrm{U}_{k, r}<\left(\mathrm{L}_{k, r+1}-\mathrm{U}_{k, r}\right) \times\left(1-b_{k, r}\right) \forall r \forall k \\
I_{k}^{I}=\sum_{r=1}^{R} b_{k, r} \times \mathrm{S}_{k, r} \forall k
\end{gathered}
$$

Although several objectives are considered simultaneously in this work, it is important to note that these objectives conflict with each other. To address such conflict, this work employs a multi-objective approach known as fuzzy optimization. Fuzzy optimization is a simple multi-objective optimization approach that was founded upon the fuzzy decision-making approach introduced by Bellman and Zadeh [40]. Zimmermann [41] then extended the fuzzy approach to deal with linear and non-linear programming problems that contain multiple objectives. In this approach, a continuous interdependence variable, $\lambda$, which is also known as the degree of satisfaction, is introduced. Every fuzzy constraint will be satisfied partially at least to $\lambda$. Thus, the multi-objective functions in the optimization can be integrated into a single objective function within the optimization framework. 
Fuzzy optimization has been widely used to determine the optimum process alternative that considers all aspects simultaneously based on the pre-defined limits. The fuzzy optimization model is expressed as:

$$
\begin{gathered}
\lambda=\sum_{k=1}^{K} \lambda_{k} b_{k} \\
\sum_{k=1}^{K} b_{k}=1
\end{gathered}
$$

where integer variable, $b_{k}$ is used to indicate the existence (or absence) of $\lambda_{k}$ of process $k$. Note that the formulation in Equation (24) results in the model being non-linear. The optimization objective of $\lambda$ is maximized, subject to the predefined upper and lower bounds. All flexible targets (GP, HQI, ISI and WAR) are predefined as fuzzy goals which are given by a linear membership function bounded by the upper $\left(\mathrm{GP}^{\mathrm{U}}, \mathrm{HQI}^{\mathrm{U}}, \mathrm{ISI}^{\mathrm{U}}, \mathrm{WAR}^{\mathrm{U}}\right)$ and lower limits $\left(\mathrm{GP}^{\mathrm{L}}, \mathrm{HQI}^{\mathrm{L}}, \mathrm{ISI}^{\mathrm{L}}, \mathrm{WAR}^{\mathrm{L}}\right) . \lambda$ of each processes $k$ is determined using Equations (26)-(29):

$$
\begin{array}{ll}
\frac{G P_{k}-\mathrm{GP}^{\mathrm{L}}}{\mathrm{GP}^{\mathrm{U}}-\mathrm{GP}^{\mathrm{L}}} \geq \lambda_{k} & \forall k \\
\frac{\mathrm{WAR}^{\mathrm{U}}-W A R_{k}}{\mathrm{WAR}^{\mathrm{U}}-\mathrm{WAR}^{\mathrm{L}} \geq \lambda_{k}} & \forall k \\
\frac{\mathrm{ISI}^{\mathrm{U}}-I S I_{k}}{\mathrm{ISI}^{\mathrm{U}}-\mathrm{ISI}^{\mathrm{L}} \geq \lambda_{k}} & \forall k \\
\frac{\mathrm{HQI}^{\mathrm{U}}-H Q I_{k}}{\mathrm{HQI}^{\mathrm{U}}-\mathrm{HQI}^{\mathrm{L}}} \geq \lambda_{k} & \forall k
\end{array}
$$

Following this, the model is solved via fuzzy optimization to select a more sustainable process configuration based on the aforementioned four objectives. Based on the optimized solution, the operating capacities, $x_{j, k}$ of the selected process configuration are then examined. If the operating capacities do not differ from the values used in the preliminary simulation, then the selected process $k$ can be recommended for the next process design phase. However, if the operating capacities do differ from the preliminary simulation, the selected process $k$ would be re-simulated in accordance to the optimized operating capacities. Once the selected process $k$ is re-simulated, the operating capacities are checked. In the event where the operating capacities in the simulation exceed an allowable error margin (i.e., $\geq 10 \%$ ), the preliminary simulation must be revisited for troubleshooting. For cases where the operating capacities are within the allowed error margin, the re-simulated conditions for process $k$ can be recommended for the next process design phase. Note that the error margin can be changed based on several factors such as type of industry, experience and knowledge of the decision-maker, and type of equipment used.

\section{Case Study}

To illustrate the proposed framework, a case study on 1,4-butanediol $\left(\mathrm{C}_{4} \mathrm{H}_{10} \mathrm{O}_{2}\right)$ production process is presented. 1,4-butanediol is a colorless and non-corrosive solution which is widely used as a solvent in the industry to manufacture elastic fibers, technical plastics and polyurethanes [42]. Based on literature review, Reppe [42] and Davy [43,44] processes are the two common and well-established alternative processes available to produce 1,4-butanediol. Table 1 shows the reaction pathway for both processes. 
Table 1. Reaction pathway for the production of 1,4-Butanediol $\left(\mathrm{C}_{4} \mathrm{H}_{10} \mathrm{O}_{2}\right)$.

\begin{tabular}{ccc}
\hline Path & Reaction & Chemical Reaction \\
\hline \multirow{2}{*}{ Reppe Process } & Hydrogenation of Acetylene and Formaldehyde & $\mathrm{C}_{2} \mathrm{H}_{2}+2 \mathrm{CH}_{2} \mathrm{O} \rightarrow \mathrm{C}_{4} \mathrm{H}_{6} \mathrm{O}_{2}$ \\
Davy Process & Hydrogenation of Dimethyl Maleate & $2 \mathrm{H}_{2}+\mathrm{C}_{4} \mathrm{H}_{6} \mathrm{O}_{2} \rightarrow \mathrm{C}_{4} \mathrm{H}_{10} \mathrm{O}_{2}$ \\
\hline
\end{tabular}

As shown in Table 1, the raw materials needed for Reppe process are formaldehyde $\left(\mathrm{C}_{2} \mathrm{H}_{2}\right)$, acetylene $\left(\mathrm{CH}_{2} \mathrm{O}\right)$ and hydrogen $\left(\mathrm{H}_{2}\right)$. Formaldehyde and acetylene are fed into two batch reactors which operate at 5 bar, $80^{\circ} \mathrm{C}$ and are arranged in parallel. Formaldehyde is reacted with acetylene in the presence of copper, bismuth and silicon dioxide supporting catalyst to produce 1,4-butynediol as an intermediate product with a conversion rate of $60 \%$. Aqueous sodium hydroxide and hydrochloric acid are used to maintain the $\mathrm{pH}$ of the medium in the reactor within the range of $\mathrm{pH} 6$ to 8 . Based on the reaction, process synthesis is started by establishing the remaining unit operations in the process. For example, the product from the batch reactors is sent to a buffer tank and is stored for approximately 1-30 $\mathrm{h}$ before feeding to a distillation column for further separation. After separation, the bottom product stream of the distillation column is rich in 1,4-butynediol and is fed to a trickling and hydrogenation reactor for further reaction to produce 1,4-butanediol as the main product with a conversion rate of $90 \%$. The operating condition of this reactor is $160{ }^{\circ} \mathrm{C}$ and 150 bar. Figure 3 shows the process flow diagram for the Reppe process.

For the Davy process, the raw materials are dimethyl maleate (DMM), $\mathrm{C}_{6} \mathrm{H}_{8} \mathrm{O}_{4}$ and hydrogen, $\mathrm{H}_{2}$. DMM is completely vaporised with $\mathrm{H}_{2}$ before feeding into the first fixed bed reactor. The fixed bed reactor operates at $15 \mathrm{bar}, 150^{\circ} \mathrm{C}$ and consists of two bed of catalysts which are palladium on alumina and copper-zinc oxide. In the reactor, DMM is fully converted into dimethyl succinate (DMS) through hydrogenation process in the presence of palladium on alumina as catalyst in the first reaction stage. In the second reaction stage, DMS is mainly converted into gammabutyrolactone (GBL) with trace amounts of tetrahydrofuran (THF) and 1,4-butanediol in the presence of copper-zinc oxide as catalyst. The conversion rate of the second reaction is $97 \%$. Based on these two reactions, process synthesis is conducted to list all the other required unit operations. For instance, the vapour-phase product from the reactor is condensed at $30^{\circ} \mathrm{C}$ and is fed into a gas-liquid separator to remove the unreacted $\mathrm{H}_{2}$. The unreacted $\mathrm{H}_{2}$ is then being recycled to the fixed bed reactor for further reaction. Then, the GBL rich stream from the first reactor is fed into the second hydrogenation reactor for further reaction to produce 1,4-butanediol with trace amounts of methanol and THF as by-products. The operating condition of the second reactor is $210{ }^{\circ} \mathrm{C}$ and 75 bar. The catalyst used in the second hydrogenation reactor is copper-zinc oxide and the conversion of GBL to 1,4-butanediol is around 95\%. The PFD for the Davy process is shown in Figure 4. The annual production rates for both Reppe and Davy process are assumed to be 60,000 tonnes of 1,4-butanediol, operating at $8000 \mathrm{~h} / \mathrm{y}$. The acceptable range of fluctuation on the amount of the product output given by the decision maker is within $\pm 30 \%$. The average height of the main unit operations in the process is assumed to be below $7 \mathrm{~m}$ [45]. Wind speed is assumed to be $4 \mathrm{~m} / \mathrm{s}$, which is a typical value for outdoor facilities, since local average wind speed is not available [45].

Based on the information mentioned above, process simulation can be performed to analyse the performance for both Reppe and Davy processes. In this work, both processes are simulated with the aid of commercial process simulation software, Aspen HYSYS version 8.8 (Aspentech, Bedford, MA, USA, 2014) [46] (see simulation flowsheets in Figures S1,S2 and simulation files in Supplementary Materials respectively). Settings and parameters used for both simulations are summarized in Tables S1 and S2 (Supplementary Materials) respectively.

Based on the simulation result, data such as input and output mass flow rates and energy consumption are then extracted. The extracted data was then used to develop the input-output models for both processes (see Tables S3 and S4 in Supplementary Materials). 
In the following step, the input-output models are evaluated based on economic, environmental, health and safety aspects. For the environmental aspects, the weighting factor of the impact at category $l, \alpha_{l}$ is assumed as one. This indicates that the impact for each category is equally important. Meanwhile, Table 2 shows the information obtained for both Reppe and Davy processes prior to the optimisation step. As shown in Table 2, the Davy process has higher initial GP and WAR; however, with a lower score of HQI and ISI, compared with the Reppe process. The latter has a lower initial GP mainly due to its higher cost of raw materials. Its higher HQI score is mainly due to the presence of harmful chemical components in the process, such as formaldehyde and 1,4-butynediol. Note that the threshold limit (TLV) of formaldehyde and 1,4-butanediol are very low, that is, $1.228 \mathrm{mg} / \mathrm{m}^{3}$ and $0.5 \mathrm{mg} / \mathrm{m}^{3}$ respectively. Besides, the higher ISI score for the Reppe process is mainly due to its highly exothermic side reaction involving formaldehyde, acetylene and hydrogen to form 2-propanol. Note that the Reppe process has a lower score of WAR (i.e., it is safer) because it converts the hazardous raw material (formaldehyde) to a product (1,4-butanediol) with a lower environmental impact. As such, the selection between these two processes is complex, particularly when four different aspects are considered simultaneously. 


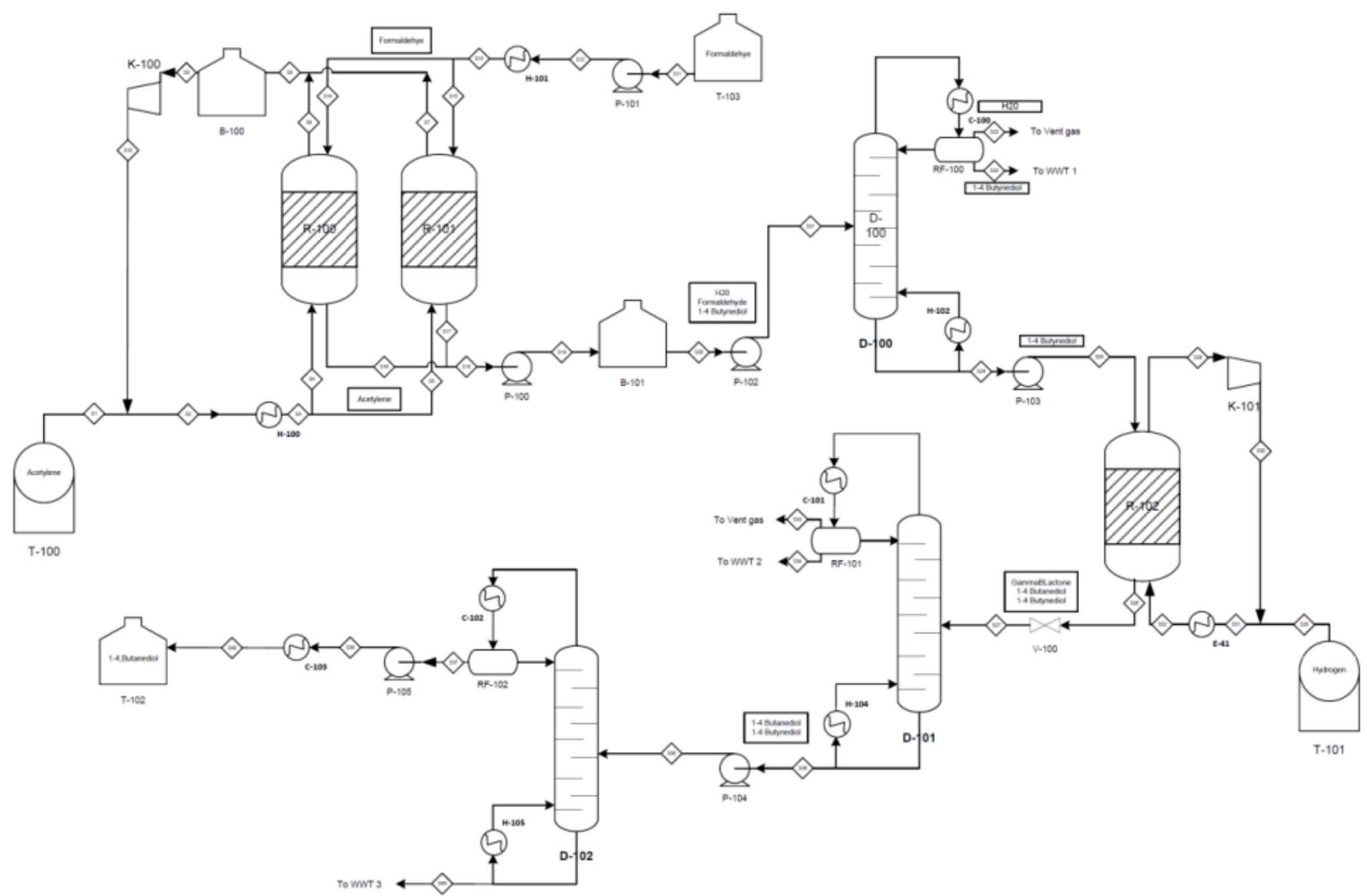

Figure 3. Process flow diagram of the Reppe Process. 


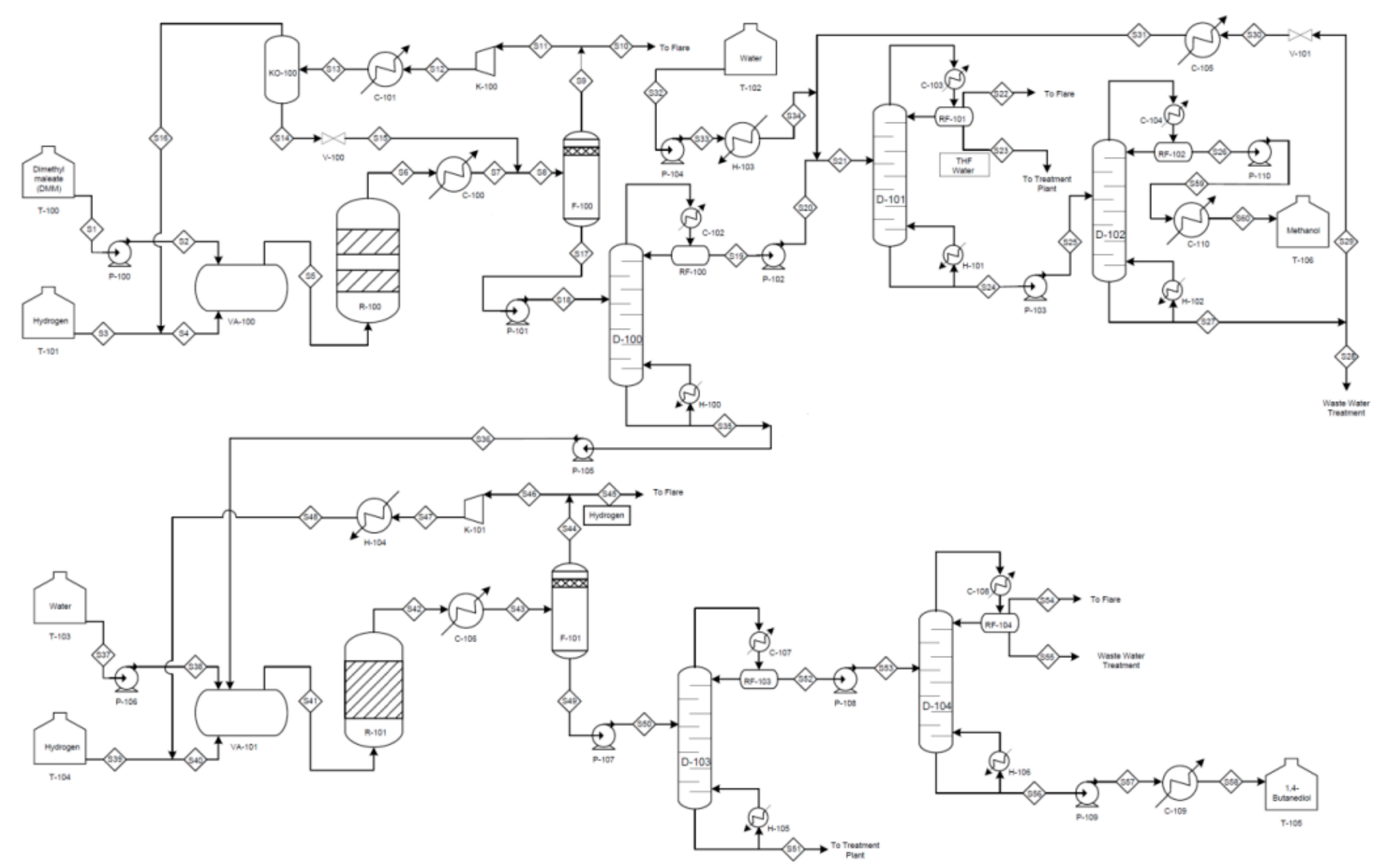

Figure 4. Process flow diagram of the Davy Process. 
Table 2. Data obtained for Reppe and Davy processes before optimisation.

\begin{tabular}{ccc}
\hline Aspects & Reppe Process & Davy Process \\
\hline$G P_{k}\left(10^{6} \mathrm{USD} / \mathrm{y}\right)$ & 45.633 & 123.408 \\
$H Q I_{k}$ & 0.484 & 0.025 \\
$I S I_{k}$ & 36 & 28 \\
$W A R_{k}$ & 2.091 & 33.679 \\
\hline
\end{tabular}

In order to determine the optimum process with consideration of all aspects simultaneously, fuzzy optimisation is used. Based on Equations (26)-(29), it is noted that lower and upper limits for GP, HQI, ISI and WAR are required. To obtain these values, $G P_{k}$ is first maximized to determine the upper limit $\mathrm{GP}^{\mathrm{U}}$. The corresponding values for $H Q I_{k}, I S I_{k}$ and $W A R_{k}$ are used as upper limits in $\mathrm{HQI} \mathrm{U}^{\mathrm{U}}$, ISI ${ }^{\mathrm{U}}$ and $\mathrm{WAR}^{\mathrm{U}}$ respectively. Following this, $W A R_{k}$ is minimized to determine $\mathrm{WAR}^{\mathrm{L}}$. The corresponding $G P_{k}$, $I S I_{k}$ and $W A R_{k}$ values were taken as lower limits $\mathrm{GP}^{\mathrm{L}}, \mathrm{HQI}^{\mathrm{L}}$ and $\mathrm{ISI}^{\mathrm{L}}$ respectively. The obtained values for $\mathrm{GP}^{\mathrm{U}}, \mathrm{GP}^{\mathrm{L}}, \mathrm{HQI}^{\mathrm{U}}, \mathrm{HQI}^{\mathrm{L}}$, $\mathrm{ISI}^{\mathrm{U}}$, $\mathrm{ISI}^{\mathrm{L}}$, $\mathrm{WAR}^{\mathrm{U}}$ and $\mathrm{WAR}^{\mathrm{L}}$ are $185.112 \times 10^{6} \mathrm{USD} / \mathrm{y}, 22.817 \times 10^{6} \mathrm{USD} / \mathrm{y}$, $0.593,0.017,36,27,50.519$ and 1.045 respectively. The model is then solved by maximizing $\lambda$ in Equation (24) with constraints in Equations (1)-(23) and (26)-(29). The model was solved using LINGO version 14.0 (Lindo Systems, Chicago, IL, USA, 2015) on a Lenovo P700 with 8 GB RAM and

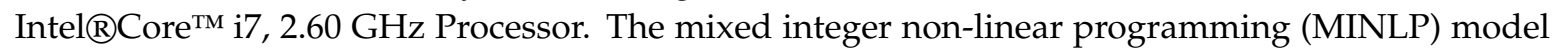
consists of 187 variables, 6 integers and 341 constraints.

Based on the results obtained, the Davy process was selected as it has a higher value of $\lambda$, that is, 0.467 , as compared to that of the Reppe process (0.111). The production of 1,4-butanediol after optimisation is scaled down from 7.9 ton/h to $7.64 \mathrm{ton} / \mathrm{h}$, which is within the acceptable range for the amount of product output. Table 3 shows the comparison of the four aspects before and after optimisation for the Davy process.

Table 3. Comparison of the four aspects for the Davy process before and after optimisation step.

\begin{tabular}{ccc}
\hline Aspects & Before & After \\
\hline Capacity of process, $x_{j, k}$ & 1 & 0.967 \\
$G P_{k}\left(10^{6}\right.$ USD/y) & 123.408 & 119.293 \\
$H Q I_{k}$ & 0.0246 & 0.0242 \\
$I S I_{k}$ & 28 & 28 \\
$W A R_{k}$ & 33.679 & 32.556 \\
\hline
\end{tabular}

After optimisation, it is observed that the operating capacity of the process has been scaled down by $3.3 \%$ from the target production to obtain a trade-off among economic, health, safety and environmental aspects. The reason for this is that, in order to achieve the trade-off solution shown in Table 3, the operating capacity for the Davy process has to be scaled down by 3.3\%. From here, the new scaled down operating capacity of the Davy process is re-simulated to study the deviations. The net output of the process streams obtained from the developed model has a slight difference to the solution generated from process simulator with a deviation of less than $10 \%$. This is mainly due to the different models used in generating the solution. The solution obtained by the mathematical model is linear, while that used by the process simulator is in rigorous mode. Since the deviation obtained is small, the selected Davy process with its optimized operating capacity can be recommended for the next stage of design.

\section{Conclusions}

In conclusion, this work presented a systematic framework to screen and select a sustainable chemical process at the preliminary design stage. The presented framework consists of three main tasks. First, process simulation was carried out to analyse the performance of each alternative process. Based on the simulation, process data such as mass flow rates and energy requirements for each process 
unit were determined. These data were then used in the next task, which is to develop an input-output model for each process. Each input-output model was formulated to address four conflicting objectives. These four objectives, namely economic performance, health, safety and environment aspects were assessed using gross profit (GP), the Health Quotient Index (HQI), the Inherent Safety Index (ISI) and the WAR algorithm respectively. Following this, fuzzy optimization was used in the third task to optimize the abovementioned aspects simultaneously and to select the most sustainable process. A sustainable process in this context refers to the process with the highest degree of satisfaction $(\lambda)$ among all four aspects considered. The proposed framework was illustrated with a case study on 1,4-butanediol production, where the proposed framework was used to determine the most sustainable process to produce 1,4-butanediol. Two processes, namely the Reppe and Davy processes were considered. Each process was simulated using Aspen HYSYS Version 8.8 and subsequently underwent input-output modelling. The developed input-output models were then optimized using fuzzy optimization. Results from the case study indicate that the Davy process is more sustainable compared to the Reppe process. In particular, the Davy process had the highest $\lambda$ value. Furthermore, the results suggest that the operating capacity of the Davy process should be scaled down by $3.3 \%$ to meet the trade-off scores determined by the $\lambda$ value obtained. Based on this recommendation, the Davy process was re-simulated. It was found that there was a small percentage of deviations between the mathematical and process simulation models. This proved that the developed model is feasible for determining a more sustainable process configuration. For future work, a selection of different unit operations may be incorporated into the model to determine their impact on flowsheet selection.

Supplementary Materials: The following are available online at http://www.mdpi.com/2227-9717/7/4/200/s1, Figure S1: Simulation Flowsheet of Davy Process via Aspen HYSYS version 8.8; Figure S2: Simulation Flowsheet of Reppe Process via Aspen HYSYS version 8.8; Table S1: Simulation Settings for Davy Process; Table S2: Simulation Settings for Reppe Process; Table S3: Input-Output Table for Reppe Process; Table S4: Input-Output Table for Davy Process; Simulation File for Davy Process (Filename: Davy Process); Simulation File for Reppe Process (Filename: Reppe Process).

Author Contributions: Conceptualization, D.C.Y.F. and D.K.S.N.; methodology, S.Y.T., K.B.C., D.C.Y.F., D.K.S.N. and M.H.H.; software, S.Y.T., K.B.C., B.H.H., A.J.W.L. and V.A.; validation, V.A. and D.K.S.N.; formal analysis, S.Y.T., K.B.C. and B.H.H.; investigation, S.Y.T., K.B.C., B.H.H.; resources, D.K.S.N.; data curation, B.H.H., A.J.W.L.; writing—original draft preparation, S.Y.T., V.A.; writing—review and editing, V.A., D.C.Y.F., M.H.H. and D.K.S.N.; visualization, S.Y.T.; supervision, V.A., D.C.Y.F., M.H.H. and D.K.S.N.

Funding: This research was funded by Ministry of Higher Education, Malaysia through the LRGS Grant (LRGS/2013/UKM-UNMC/PT/05).

Acknowledgments: The authors would like to acknowledge the financial support provided from the Ministry of Higher Education, Malaysia through the LRGS Grant (LRGS/2013/UKM-UNMC/PT/05).

Conflicts of Interest: The authors declare no conflict of interest.

\section{Nomenclature}

$\begin{array}{ll}\text { Index/Subscript } \\ p & \text { Index for stream of input or output } \\ j & \text { Index for unit operations } \\ k & \text { Index for alternative process } \\ a & \text { Index for chemical components } \\ l & \text { Index for environmental impact category } \\ r & \text { Index for criteria with a given range } \\ \text { Parameters } & \\ \mathrm{a}_{p, j, k} & \text { Matrix of input or output mass flow rate for stream } p \text { to or from unit operation } j \text { of process } k \\ \mathrm{x}_{j, k}^{\mathrm{L}} & \text { Lower limit of the capacity for unit operation } j \text { in process } k \\ \mathrm{x}_{j, k}^{\mathrm{U}} & \text { Upper limit of the capacity for unit operation } j \text { in process } k \\ \mathrm{AOT}_{k} & \text { Annual operating time for process } k \\ \mathrm{C}_{p, k}^{\text {Prod }} & \text { Product price of output } p \text { (products) in process } k \\ \mathrm{C}_{p, k}^{\mathrm{Raw}} & \text { Cost of input } p \text { (raw materials) in process } k\end{array}$


$\mathrm{EP}^{\mathrm{L}} \quad$ Lower limit for gross profit

$\mathrm{EP}^{\mathrm{U}} \quad$ Upper limit for gross profit

$W_{A R}{ }^{L} \quad$ Lower limit for environmental impact

WAR ${ }^{\mathrm{U}} \quad$ Upper limit for environmental impact

ISI $^{\mathrm{L}} \quad$ Lower limit for inherent safety index

$\mathrm{ISI}^{\mathrm{U}} \quad$ Upper limit for inherent safety index

$\mathrm{HQI}^{\mathrm{L}} \quad$ Lower limit for health quotient index

$\mathrm{HQI}^{\mathrm{U}} \quad$ Upper limit for health quotient index

$\mathrm{PEI}_{a} \quad$ Score of potential environmental impact for chemical component $a$

$\mathrm{PEI}_{a, l} \quad$ Score of potential environmental impact for chemical component $a$ at each of the category $l$

$P E I^{\text {Elec }} \quad$ Score of potential environmental impact for electricity

$\alpha_{l} \quad$ Weighting factor of the impact at category $l$

$\mathrm{FE}_{i, j, k} \quad$ Estimated fugitive emission rates in stream $i$ to or from unit operation $j$ in process $k$

$\mathrm{A}_{k}^{\mathrm{T}} \quad$ Total process floor area in process $k$

$\mathrm{A}_{j, k} \quad$ The floor area of each unit operations $j$ in process $k$

$s_{k} \quad$ Side length of the process $k$

$\mathrm{A}_{k}^{\mathrm{c}} \quad$ Cross-sectional area of process $k$

$h_{k} \quad$ Average height of the main unit operations in process $k$

$\mathrm{Q}_{k} \quad$ Air volumetric flow rate in process $k$

$\mathrm{V} \quad$ Wind speed

$C_{a, k} \quad$ Average concentration of chemical components $a$ in the air at downwind edge of the plot area

$\mathrm{C}_{a}^{\mathrm{EL}} \quad$ Threshold limit of the chemical component $a$

$\mathrm{L}_{k, r} \quad$ Lower bound for a given criteria $r$ in process $k$

$\mathrm{U}_{k, r} \quad$ Upper bound for a given criteria $r$ in process $k$

$\mathrm{S}_{k, r} \quad$ Score of sub-index for inventory in process $k$ based on a given criteria $r$

Variables

$\mathrm{x}_{j, k}$

$\mathrm{y}_{p, k}$

$y_{p, k}^{\text {Out }}$

$y_{p, k}^{\text {In }}$

$y_{p, k}^{\text {Elec }}$

$\mathrm{w}_{a, j, k}$

$m_{a, k}$

$G P_{k}$

$W A R_{k}$

$i_{k}^{(\mathrm{cp}) \text {,out }}$

$i_{k}^{(\mathrm{cp}), \text { in }}$

$i_{k}^{(\text {ep }) \text {,out }}$

$i_{k} \mathrm{CI}$

$I_{k}$ PI

Capacity or size of the unit operation $j$ in process $k$

Net input or output of stream $p$ in process $k$

Net output of stream $p$ in process $k$

Net input of stream $p$ in process $k$

Power consumption of process $k$

Weight composition of chemical component $a$ from unit $j$ in process $k$

Fugitive emission of each of the chemical components $a$ in process $k$

Gross profit for process $k$

Total environmental impact generated by process $k$

Output rates of impact in the process $k$

Input rates of impact in the process $k$

Impact of power consumption for process $k$

Chemical ISI score of process $k$

Process ISI score of process $k$

$I_{k}^{\mathrm{RM}, \max } \quad$ Sub-index for the factor of the heat of main reaction in process $k$

$I_{k}^{R S}$, max Sub-index for the factor of the heat of side reaction in process $k$

$I_{k}^{\mathrm{INT}, \max } \quad$ Sub-index for the factor of chemical interaction in process $k$

$I_{k}^{\mathrm{FL}, \max } \quad$ Sub-index for the factor of flammability in process $k$

$I_{k}^{\mathrm{EX}, \max } \quad$ Sub-index for the factor of explosiveness in process $k$

$I_{k}^{\mathrm{TOX}, \max } \quad$ Sub-index for the factor of toxic exposure in process $k$

$I_{k}^{\mathrm{COR}, \max } \quad$ Sub-index for the factor of corrosiveness of the chemical components in process $k$

$I_{k}^{\mathrm{I}} \quad$ Sub-index for the factor of inventory in process $k$

$I_{1}^{\mathrm{T}}, \max$

$I_{\mathrm{P}}^{\mathrm{P}}, \max$

$I_{k}^{\mathrm{EQ}, \max }$

$I_{k}^{\mathrm{ST}, \max }$

$I S I_{k}$

Sub-index for the factor of process temperature in process $k$

Sub-index for the factor of process pressure in process $k$

Sub-index for the factor of equipment safety in process $k$

Sub-index for the factor of safe process structure in process $k$

$H Q I_{a, k} \quad H Q I$ of each chemical components $a$ in process $k$ 


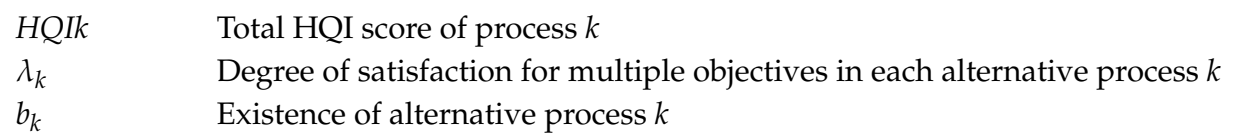

\section{References}

1. Westerberg, A.W. Recent Developments in Chemical Process and Plant Design; Liu, Y.A., Henry, A., McGee, J., Epperly, W.R., Eds.; John Wiley and Sons: New York, NY, USA, 1987.

2. Stephanopoulos, G.; Reklaitis, G.V. Process systems engineering: From Solvay to modern bio- and nanotechnology. A history of development, successes and prospects for the future. Chem. Eng. Sci. 2011, 66, 4272-4306. [CrossRef]

3. Nishida, N.; Stephanopoulos, G.; Westerberg, A.W. A review of process synthesis. AIChE J. 1981, $27,321-351$. [CrossRef]

4. Linnhoff, B.; Townsend, D.W.; Boland, D.; Hewitt, G.F.; Thomas, B.E.A.; Guy, A.R.; Marsland, R.H. User Guide on Process Integration for the Efficient Use of Energy; Institution of Chemical Engineers: Rugby, UK, 1982.

5. Foo, D.C.Y.; Ng, D.K.S. Process Integration for Cleaner Process Design. In Handbook of Process Integration: Minimisation of Energy and Water Use, Waste and Emissions; Series in Energy No. 61; Klemeš, J.J., Ed.; Woodhead Publishing: Sawston, UK, 2013.

6. Douglas, J.M. Conceptual Design of Chemical Processes; McGraw-Hill: New York, NY, USA, 1988.

7. Azapagic, A.; Millington, A.; Collett, A. A methodology for integrating sustainability considerations into process design. Chem. Eng. Res. Des. 2006, 84, 439-452. [CrossRef]

8. Azapagic, A.; Millington, A.; Collett, A. Process design for sustainability: The case of vinyl chloride monomer. In Sustainable Development in Practice: Case Studies for Engineers and Scientists; John Wiley \& Sons, Ltd.: Hoboken, NJ, USA, 2004; pp. 201-249.

9. Gentile, M.; Rogers, W.; Mannan, M. Development of a fuzzy logic-based inherent safety index. Process Saf. Environ. Prot. 2003, 81, 444-456. [CrossRef]

10. Hassim, M.; Hurme, M. Inherent occupational health assessment during preliminary design stage. J. Loss Prev. Process Ind. 2010, 23, 476-482. [CrossRef]

11. Edwards, D.; Lawrence, D. Assessing the inherent safety of chemical process routes: Is there a relation between plant costs and inherent safety? Process Saf. Environ. Prot. 1993, 71, 252-258.

12. Heikkila, A. Inherent Safety in Process Plant Design; Technical Research Centre of Finland: Espoo, Finland, 1999.

13. Palaniappan, C.; Srinivasan, R.; Tan, R. Expert system for the design of inherently safer processes. 1. Route selection stage. Ind. Eng. Chem. Res. 2002, 41, 6698-6710. [CrossRef]

14. Hassim, M.; Edwards, D. Development of a methodology for assessing inherent occupational health hazards. Process Saf. Environ. Prot. 2006, 84, 378-390. [CrossRef]

15. Hassim, M.H.; Perez, A.L.; Hurme, M. Estimation of chemical concentration due to fugitive emissions during chemical process design. Process Saf. Environ. Prot. 2010, 88, 173-184. [CrossRef]

16. Cave, S.; Edwards, D. Chemical process route selection based on assessment of inherent environmental hazard. Comput. Chem. Eng. 1997, 21, 965-970. [CrossRef]

17. Gunasekera, M.; Edwards, D. Estimating the environmental impact of catastrophic chemical releases to the atmosphere: An index method for ranking alternative chemical process routes. Process Saf. Environ. Prot. 2003, 81, 463-474. [CrossRef]

18. Gunasekera, M.; Edwards, D. Chemical process route selection based upon the potential toxic impact on the aquatic, terrestrial and atmospheric environments. J. Loss Prev. Process Ind. 2006, 19, 60-69. [CrossRef]

19. Cabezas, H.; Bare, J.; Mallick, S. Pollution prevention with chemical process simulators: The generalized waste reduction (WAR) algorithm-full version. Comput. Chem. Eng. 1999, 23, 623-634. [CrossRef]

20. Young, D.; Cabezas, H. Designing sustainable processes with simulation: The waste reduction (WAR) algorithm. Comput. Chem. Eng. 1999, 23, 1477-1491. [CrossRef]

21. Andiappan, V.; Ko, A.S.Y.; Lau, V.W.S.; Ng, L.Y.; Ng, R.T.L.; Chemmangattuvalappil, N.G.; Ng, D.K.S. Synthesis of sustainable integrated biorefinery via reaction pathway synthesis: Economic, incremental enviromental burden and energy assessment with multiobjective optimization. AIChE J. 2015, 61, 132-146. [CrossRef] 
22. Seider, W.D.; Seader, J.D.; Lewin, D.R. Product and Process Design Principles: Synthesis, Analysis and Evaluation, 2nd ed.; John Wiley \& Sons, Ltd.: Hoboken, NJ, USA, 2004.

23. Othman, M.; Repke, J.; Wozny, G.; Huang, Y. A modular approach to sustainability assessment and decision support in chemical process design. Ind. Eng. Chem. Res. 2010, 49, 7870-7881. [CrossRef]

24. Al-Sharrah, G.; Elkamel, A.; Almanssoor, A. Sustainability indicators for decisionmaking and optimisation in the process industry: The case of the petrochemical industry. Chem. Eng. Sci. 2010, 65, 1452-1461. [CrossRef]

25. Liew, W.; Hashim, M.; Ng, D.; Hurme, M. Fuzzy Optimization for Screening of Sustainable Chemical Reaction Pathways. Chem. Eng. Trans. 2012, 29, 529-534.

26. $\mathrm{Ng}$, R.; Hassim, M.; Ng, D. Process synthesis and optimization of a sustainable integrated biorefinery via fuzzy optimisation. AIChE J. 2013, 59, 4212-4227. [CrossRef]

27. Teng, W.C.; Fong, K.L.; Shenkar, D.; Wilson, J.A.; Foo, D.C.Y. Piper Diagram-A Novel Visualisation Tool for Process Design. Chem. Eng. Res. Des. 2016, 112, 132-145. [CrossRef]

28. Motard, R.L.; Shacham, M.; Rosen, E.M. Steady state chemical process simulation. AIChE J. 1975, 21, 417-436. [CrossRef]

29. Dimian, A.C.; Bildea, C.S.; Kiss, A.A. Integrated Design and Simulation of Chemical Processes, 2nd ed.; Elsevier: Amsterdam, The Netherlands, 2014.

30. Foo, D.C.Y.; Chemmangattuvalappil, N.; Ng, D.K.S.; Elyas, R.; Chen, C.-L.; Elms, R.D.; Lee, H.-Y.; Chien, I.-L.; Chong, S.; Chong, C.H. Chemical Engineering Process Simulation; Elsevier: Amsterdam, The Netherlands, 2017; ISBN 978-0-12-803782-9.

31. Leontief, W. Quantitative Input and Output Relations in the Economic Systems of the United States. Rev. Econ. Stat. 1936, 18, 105-125. [CrossRef]

32. Leontief, W.W. The Structure of the AMERICAN Economy; Oxford University Press: New York, NY, USA, 1951.

33. Tan, R.; Culaba, A.; Aviso, K. A fuzzy linear programming extension of the general matrix-based life cycle model. J. Clean. Prod. 2008, 16, 1358-1367. [CrossRef]

34. Aviso, K.; Tan, R.; Culaba, A.; Cruz, J., Jr. Fuzzy input-Output model for optimizing eco-industrial supply chains under water footprint constraints. J. Clean. Prod. 2011, 19, 187-196. [CrossRef]

35. Kasivisvanathan, H.; Barilea, I.D.U.; Ng, D.K.S.; Tan, R.R. Optimal Operational Adjustment in Multi-functional Energy Systems in Response to Process Inoperability. Appl. Energy 2013, 102, 492-500. [CrossRef]

36. Kasivisvanathan, H.; Ubando, A.T.; Ng, D.K.S.; Tan, R.R. Robust Optimization for Process Synthesis and Design of Multifunctional Energy Systems with Uncertainties. Ind. Eng. Chem. Res. 2014, 53, 3196-3209. [CrossRef]

37. Foong, S.Z.Y.; Goh, C.K.M.; Supramaniam, C.V.; Ng, D.K.S. Input-Output optimisation model for sustainable oil palm plantation development. Sustain. Prod. Consum. 2019, 17, 31-46. [CrossRef]

38. Andiappan, V.; Ng, D.S.; Tan, R.R. Design operability and retrofit analysis (DORA) framework for energy systems. Energy 2017, 134, 1038-1052. [CrossRef]

39. El-Halwagi, M.M. Process Integration; Academic Press: Cambridge, MA, USA, 2006.

40. Bellman, R.E.; Zadeh, L.A. Decision making in a fuzzy environment. Manag. Sci. 1970, 17, $141-164$. [CrossRef]

41. Zimmermann, H. Fuzzy programming and liner programming with several objective functions. Fuzzy Sets Syst. 1978, 1, 45-55. [CrossRef]

42. Haas, T.; Jaeger, B.; Weber, R.; Mitchell, S.; King, C. New diol processes: 1,3- propanediol and 1,4-butanediol. Appl. Catal. A Gen. 2005, 1, 83-88. [CrossRef]

43. Schlander, J.; Turek, T. Gas-phase hydrogenolysis of dimethyl maleate to 1,4- butanediol and -butyrolactone over copper/zinc oxide catalysts. Ind. Eng. Chem. Res. 1999, 4, 1264-1270. [CrossRef]

44. Bertola, A. Process for the production of Tetrahydrofuran, Gammabutyrolactone and Butanediol. U.S. Patent 6248906B1, 19 June 2001.

45. Mecklenburgh, J.C. Process Plant Layout; Halstead Press: New York, NY, USA, 1985.

46. Aspentech. Getting Started in Aspen HYSYS; Aspen Technology, Inc.: Bedford, MA, USA, 2014.

(C) 2019 by the authors. Licensee MDPI, Basel, Switzerland. This article is an open access article distributed under the terms and conditions of the Creative Commons Attribution (CC BY) license (http://creativecommons.org/licenses/by/4.0/). 